\title{
Outcomes and Cost Effectiveness of a Respiratory Coordinated Care Program in Patients with Severe or Very Severe COPD
}

\author{
Shahila Aslam1, Johnathan Man1, Jason Behary', John Riskallah1, Saidul Ansary', \\ Benjamin CH Kwan'1,2 \\ ${ }^{1}$ Department of Respiratory and Sleep Medicine, The Sutherland Hospital, Sydney, Australia \\ ${ }^{2}$ St George and Sutherland Hospitals Clinical School of Medicine, University of New South Wales, Sydney, \\ Australia \\ Email: ben.kwan@health.nsw.gov.au
}

Received 8 August 2016; accepted 23 August 2016; published 26 August 2016

Copyright (C) 2016 by authors and Scientific Research Publishing Inc.

This work is licensed under the Creative Commons Attribution International License (CC BY).

http://creativecommons.org/licenses/by/4.0/

(c) (i) Open Access

\begin{abstract}
Multidisciplinary community coordinated care programs are widely adopted to optimise care of chronic disease patients, but there is a need for further evaluation in the setting of COPD. This observational study evaluated 147 patients with severe or very severe COPD who were enrolled in a multidisciplinary community respiratory coordinated care program (RCCP) from 2007 to 2012. Comparison was made of hospitalisation rates and length of stay for 12 months prior to joining the program, and the first 12 months after joining the program. This data was used to inform a cost analysis. Enrolment into RCCP halved the annual hospital admission rate from 1.18 to 0.57 admissions per year (relative risk reduction $51.4 \%, p<0.001$ ), and annual total length of stay was reduced from 8.06 to 3.59 days per patient per year $(p<0.001)$. Hospital admissions were reduced from 5.05 days to 2.00 days $(p<0.001)$. Accounting for the program's costs, these changes resulted in a \$US 906.94 (\$AUD 972.80) cost saving per patient per year. A RCCP program can reduce patient hospitalisation and overall costs in the COPD setting.
\end{abstract}

\section{Keywords}

Chronic Obstructive Pulmonary Disease, Cost-Effectiveness Analysis, Hospitalization, Length of Stay, Model of Care

\section{Introduction}

Chronic Obstructive Pulmonary Disease (COPD) is a significant cause of global morbidity and mortality (Vestbo, 
Hurd [1]), a major cause of severe exacerbations requiring hospitalization [2] and a source of an increasing burden of disease in the context of an ageing population [3].

In the United States, the financial burden of COPD is estimated to be $\$ 50$ billion US dollars (USD), $\$ 30$ billion in direct health care expenditure and \$20 billion in indirect expenditure, with the mean cost of hospital admission at \$7,100 [4]. In Europe, COPD is estimated to have a cost of 50 billion Euros with a similar division in direct and indirect costs, and further financial loss from loss of disability-adjusted life years [5]. In Australia, the annual disease cost in 2012 was estimated at greater than \$900 million Australian dollars (\$839 million USD) contributing to the largest share of national health spending and the second highest rate of avoidable hospital admissions [6].

Multidisciplinary community coordinated care programs aim to improve the outpatient management of patients and the link between outpatient and inpatient care. The goal is to improve patient health outcomes, reduce hospitalization, and reduce health care costs through the use of a well coordinated multidisciplinary team [7] with an emphasis on early prevention, early access to specialist advice, self management, and chronic as well as acute care. A key part of the service is to prevent late reporting of exacerbation symptoms [8] by regular health professional review and treat exacerbations early when it is still safe to do so in an outpatient setting, benefiting both the patient and the hospital system [9].

A metanalysis on integrated disease management interventions in COPD found modest benefit in quality of life and hospital length of stay [10], while the cost effectiveness of such programs is unproven [11]. Worldwide, these programs continue to be developed and evaluated with the aim of meeting the challenges posed by COPD to the health system [10] [12] [13].

We conducted a retrospective review of a long running multicentre multidisciplinary coordinated care COPD program in Australia, with the aim of adding to the body of evidence evaluating these programs around the world. The primary aim was to assess any difference in hospitalization rates in the 12 months prior to enrolling in the program compared to the first 12 months after joining the program. Its secondary aim was to determine if such a program is cost effective.

\section{Methods}

Ethics approval was obtained from the Human Research Ethics Committees of the participating hospitals. Patient records were deidentified prior to analysis.

\subsection{Patients}

Patients with chronic respiratory disease residing in the catchment area of two hospital sites (St George Hospital, Sydney, Australia; The Sutherland Hospital, Sydney, Australia) were enrolled into a multidisciplinary respiratory coordinated care program (RCCP) between January 2007 and December 2012. The program was designed for patients with severe or very severe COPD to reduce hospitalisations.

Inclusion criteria involved 1) formal diagnosis of COPD as per GOLD guidelines (1), 2) FEV1 <50\% predicted (lower limit of normal criterion) 3) Care optimized by a respiratory physician, 4) Consent from patient's general physician (GP) for enrolment in the program, 5) Psychosocially stable, 6) Residing in the regional area for $>12$ months. Patients were excluded from the study analysis if there were co-existent chronic respiratory conditions other than COPD, unclear hospital records regarding admissions in the past 12 months, incomplete records ( $>25 \%$ information missing), or became deceased within 12 months of study enrollment. Patients were not required to have ceased smoking before enrollment.

Data regarding age, sex, home oxygen status and hospital admissions were prospectively collected until the patient was discharged from the program or became deceased.

\subsection{Intervention}

The RCCP program provides a multidisciplinary service involving medical, nursing and allied health professionals including physiotherapists and occupational therapists. The service provides home visits on a weekly, fortnightly or monthly basis, individualised case management, reviews of patient compliance, patient education, equipment supply and referral to pulmonary rehabilitation. Recognition of early clinical deterioration prompts an action plan whereby the community nurse will directly contact a respiratory physician or senior registrar, and 
early community treatment such as antibiotics, bronchodilators and steroids can be implemented. The service also provides close follow up of patients post discharge from hospital in order to facilitate ongoing recovery from their illness, and allows more rapid discharge from hospital. The service is fully funded by the involved public hospitals. Staff requirements and costs are outlined in the Supplementary Content. Patients can be enrolled in the program by GPs, respiratory physicians or inpatient hospital teams.

\section{Assessment}

COPD patients who had enrolled during 2007-2012 were identified through the program's records and then deidentified for analysis. Data regarding respiratory admission rates and length of stay was obtained from the program database, and confirmed by a secondary search through the hospital electronic database and medical record files. Only hospital admissions related to a primary respiratory problem were included, including hospital codings of "COPD", "exacerbation of COPD", "emphysema", "bronchitis", "pneumonia” and "respiratory infection”. The annual hospital admission rate, annual length of stay (LOS) and average LOS per hospital admission was calculated for each enrolled patient for the twelve months prior to joining the program and for the twelve months after joining the program.

\section{Statistical Analysis}

Analysis was performed using SPSS, version 20.0 statistical software (IBM SPSS Statistics, Armonk, New York). Admission rates before and after joining the program were compared by paired t-test, and multiple regression analyses based upon pooled ordinary least squares, fixed effects and random effects estimators were used to assess the effect of age, sex and use of home oxygen. A p-value of $<0.05$ was applied for all statistical tests.

Costing analysis was performed by accounting for the total program costs, including staff salaries, motor vehicle costs, medications and medical equipment, and calculating a cost of the program per patient. This was offset against savings made from changes in hospital admission rates and bed days, with 1 hospital bed day of a COPD admission conservatively estimated at \$USD 530 based on the available literature [14] [15]. All costings are reported in US dollars. The foreign currency exchange rate calculation between AUD and USD is based on the averaged end of calendar year rate between 2007 to 2012 published by the Australian Taxation Office which ranged from 0.8448 USD = 1AUD in 2007 to 1.0668 USD = 1AUD in 2012 with an average rate of 0.9323 USD $=1$ AUD $[16]$.

\section{Results}

\subsection{Demographics}

In total, 491 patients were enrolled in the RCCP program between 2007 and 2012. Of these 491 patients, 147 fulfilled the inclusion criteria for the study (Figure 1). The main reasons for exclusion were a primary respiratory condition other than COPD and missing information. Of the 147 included patients, there were 62 females and 85 males, with a mean age of 77 years (range from 60 to 95 years), and 31 out of 147 patients required home oxygen (Table 1).

The 147 patients studied contributed 173 admissions in the 12 months before enrolling in the program and 84 admissions in the 12 months after enrollment. This translated into a statistically significant reduction in annual hospital admission rate from 1.18 to 0.57 hospital admissions per patient per year ( $\mathrm{p}$ value $<0.001$ ), representing a relative risk reduction of $51.4 \%$ in hospital admissions. There was also a statistically significant reduction in annual total LOS per patient from 8.06 to 3.59 days $(\mathrm{p}<0.001)$ and reduction in LOS per admission from 5.05 to 2.00 days $(\mathrm{p}<0.001)$ (Table 2$)$.

These results remained significant after adjusting for age, sex and use of home oxygen. These variables were not found to influence the effectiveness of the program (Table 3).

\subsection{Cost}

The average annual cost of the program was $\$$ US 716,939. The majority of the cost was on staff salaries (Supplementary Content). The salary of 1 FTE nursing or physiotherapist was $\$$ US 57,803 - 72,719. Other costs 


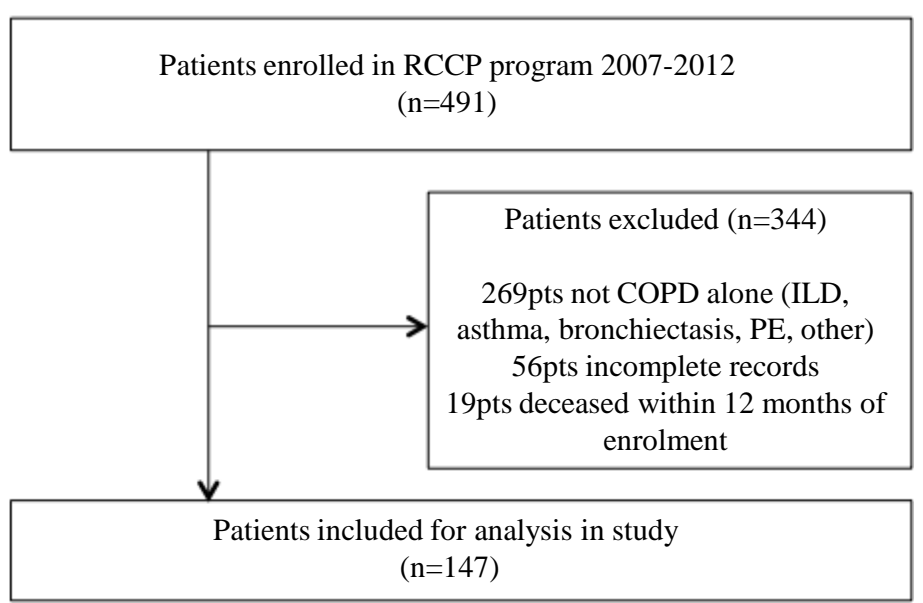

Figure 1. Flow diagram showing inclusion and exclusion of patients.

Table 1. Baseline characteristics of included patients.

\begin{tabular}{ll}
\hline Total Number of Patients & 147 \\
Male & 85 \\
Female & 62 \\
Age (median) & 77 \\
Age (range) & $64-87$ \\
Home $\mathrm{O}_{2}$ & 31 \\
No Home $\mathrm{O}_{2}$ & 116 \\
\hline
\end{tabular}

Table 2. Impact of RCCP on hospital admission rate, total length of stay per year, and length of stay per hospital admission.

\begin{tabular}{|c|c|c|c|c|}
\hline & $\begin{array}{l}12 \text { months } \\
\text { Pre-enrolment }\end{array}$ & $\begin{array}{l}12 \text { months } \\
\text { Post-enrolment }\end{array}$ & Relative Risk Reduction & \\
\hline $\begin{array}{l}\text { Hospital admission rate } \\
\text { (per patient/year) }\end{array}$ & 1.18 & 0.57 & $51.7 \%$ & $\mathrm{p}<0.001$ \\
\hline $\begin{array}{l}\text { Total length of stay per } \\
\text { year (days per patient) }\end{array}$ & 8.06 & 3.59 & $55.5 \%$ & $\mathrm{p}<0.001$ \\
\hline $\begin{array}{l}\text { Length of stay per hospital } \\
\text { admission (days) }\end{array}$ & 5.05 & 2.00 & $60.4 \%$ & $\mathrm{p}<0.001$ \\
\hline
\end{tabular}

Table 3. P-values for impact of age, sex and use of home oxygen on admission rate and length of stay.

\begin{tabular}{ccc}
\hline & Admission Rate & Length of Stay \\
\hline Age & 0.665 & 0.84 \\
Sex & 0.961 & 0.35 \\
Use of Home Oxygen & 0.093 & 0.39 \\
\hline
\end{tabular}

include administration costs, motor vehicle costs, medications and medical equipment. The total cost of the program per patient was \$US 1460.13 per year.

Estimating the average daily cost of a COPD admission to be \$US 530 based on available literature18, 19, the 4.47 day reduction in hospital admissions per patient equates to \$US 2367.07 saved per patient per year. This equates to a net cost saving per patient of \$US 906.94 per year.

\section{Discussion}

This multicentre review of a large respiratory coordinated care program spanning 5 years in an Australian 
population with severe and very severe COPD does demonstrate a statistically and clinically significant improvement in rates of hospitalisation and also demonstrates cost effectiveness, accounting for the running costs of the program. We believe that hospital admission rates can be used as a surrogate marker for health care outcomes for these patients, suggesting improved health outcomes in these patients as well.

The results of this study are consistent with global data which suggest the benefit of such programs is seen most significantly in patients with more severe COPD as the potential to reduce hospitalization is greater.

The strength of this study lies in the relatively large number of subjects, and the ability to evaluate this model of care in a clinically relevant subset of patients, namely patients with severe and very severe COPD. However, we acknowledge limitations of the study. The main concern is the potential for selection bias given the large number of excluded patients. One of the main reasons for exclusion was the considerable amount of missing data, which also meant that we were unable compare patient characteristics of the excluded subjects with the included subjects. There was also insufficient data to guide analysis on relevant confounders such as FEV1, exercise tolerance, comorbidities, changes in smoking habit, education or occupation, passive smoking exposure, work or traffic exposure and number of coinhabitants, all of which we ideally would have liked to assess. Given the multisystem effects of COPD, hospital admissions for non respiratory illnesses may also have been of interest but were not included in our assessments.

We decided to exclude patients who became deceased within 12 months of the study was due to the analysis' reliance on hospitalization rates over a full 12 month period. We felt that, for example, a patient who died after 6 months would falsely improve the results of the program in reducing hospitalization, so the conservative approach would be to exclude such patients completely. However, we also acknowledge this is a clinically significant group of patients with likely the most severe COPD, in whom the benefits of the program remain unknown. Our decision to limit the study to patients with COPD rather than other respiratory diseases helps to answer a clinical question for a specific population but certainly it would be beneficial to study the effects of this program in other respiratory diseases, particularly overlap syndromes which can utilize health care even more than COPD patients. Finally, we agree with the recommendations of the latest metanalysis [10] that future studies should comment on effects on quality of life or exercise tolerance, though unfortunately we could not obtain this data for our current review.

This study adds to a body of international data which supports further evaluation and investment in multidisciplinary community based programs in tackling the challenges to health systems posed by an increasing global COPD burden, particularly in the subgroup of patients with severe and very severe obstructive disease.

\section{Acknowledgements}

The authors would like to express gratitude to Nick Spiliopoulos, nurse unit manager of the RCCP program, Kishor Chelliah, statistician, and Omar Salem for assistance in data preparation.

\section{Funding}

Funding was at the expense of the primary investigator.

\section{Conflicts of Interest}

No conflicts of interest declared.

\section{References}

[1] Vestbo, J., Hurd, S.S., Agusti, A.G., Jones, P.W., Vogelmr, C., Anzueto, A., et al. (2013) Global Strategy for the Diagnosis, Management, and Prevention of Chronic Obstructive Pulmonary Disease: GOLD Executive Summary. American Journal of Respiratory and Critical Care Medicine, 187, 347-365. http://dx.doi.org/10.1164/rccm.201204-0596PP

[2] Molinari, N., Briand, C., Vachier, I., Malafaye, N., Aubas, P., Georgescu, V., et al. (2015) Hospitalizations for COPD Exacerbations: Trends and Determinants of Death. Journal of Chronic Obstructive Pulmonary Disease, 12, 621-627.

[3] Burney, P.G., Patel, J., Newson, R., Minelli, C. and Naghavi, M. (2015) Global and Regional Trends in COPD mortality, 1990-2010. European Respiratory Journal, 45, 1239-1247. http://dx.doi.org/10.1183/09031936.00142414

[4] Guarascio, A.J., Ray, S.M., Finch, C.K. and Self, T.H. (2013) The Clinical and Economic Burden of Chronic Obstructive Pulmonary Disease in the USA. ClinicoEconomics and Outcomes Research, 5, 235-245. 
[5] European Respiratory Society. European Lung White Book: The Cost of Respiratory Disease 2016 [updated 4/5/16. http://www.erswhitebook.org/chapters/the-economic-burden-of-lung-disease/the-cost-of-respiratory-disease/

[6] Australian Institute of Health and Welfare (2012) Australia’s Health 2012. Health ADO, Editor, Canberra.

[7] Spencer, P. and Hanania, N.A. (2013) Optimizing Safety of COPD Treatments: Role of the Nurse Practitioner. Journal of Multidisciplinary Healthcare, 6, 53-63. http://dx.doi.org/10.2147/JMDH.S35711

[8] Langsetmo, L., Platt, R.W., Ernst, P. and Bourbeau, J. (2008) Underreporting Exacerbation of Chronic Obstructive Pulmonary Disease in a Longitudinal Cohort. American Journal of Respiratory and Critical Care Medicine, 177, 396401. http://dx.doi.org/10.1164/rccm.200708-12900C

[9] Pasquale, M.K., Sun, S.X., Song, F., Hartnett, H.J. and Stemkowski, S.A. (2012) Impact of Exacerbations on Health Care Cost and Resource Utilization in Chronic Obstructive Pulmonary Disease Patients with Chronic Bronchitis from a predominantly Medicare Population. International Journal of Chronic Obstructive Pulmonary Disease, 7, 757-764. http://dx.doi.org/10.2147/COPD.S36997

[10] Kruis, A.L., Smidt, N., Assendelft, W.J., Gussekloo, J., Boland, M.R., Rutten-van Molken, M., et al. (2013) Integrated Disease Management Interventions for Patients with Chronic Obstructive Pulmonary Disease. Cochrane Database of Systematic Reviews, 10, CD009437. http://dx.doi.org/10.1002/14651858.cd009437.pub2

[11] Steuten, L.M., Lemmens, K.M., Nieboer, A.P. and Vrijhoef, H.J. (2009) Identifying Potentially Cost Effective Chronic Care Programs for People with COPD. International Journal of Chronic Obstructive Pulmonary Disease, 4, 87-100.

[12] Chung, L.P., Lake, F., Hyde, E., McCamley, C., Phuangmalai, N., Lim, M., et al. (2016) Integrated Multidisciplinary Community Service for Chronic Obstructive Pulmonary Disease Reduces Hospitalisations. Internal Medicine Journal, 46, 427-434. http://dx.doi.org/10.1111/imj.12984

[13] Rice, K.L., Dewan, N., Bloomfield, H.E., Grill, J., Schult, T.M., Nelson, D.B., et al. (2010) Disease Management Program for Chronic Obstructive Pulmonary Disease: a Randomized Controlled Trial. American Journal of Respiratory and Critical Care Medicine, 182, 890-896. http://dx.doi.org/10.1164/rccm.200910-1579OC

[14] Hutchinson, A., Brand, C., Irving, L., Roberts, C., Thompson, P. and Campbell, D. (2010) Acute Care Costs of Patients Admitted for Management of Chronic Obstructive Pulmonary Disease Exacerbations: Contribution of Disease Severity, Infection and Chronic Heart Failure. Internal Medicine Journal, 40, 364-371. http://dx.doi.org/10.1111/j.1445-5994.2010.02195.x

[15] Lung Foundation Australia. Lung Disease in Australia 2011. http://lungfoundation.com.au/general-information/statistics

[16] Australian Taxation Office (2016) Foreign Exchange Rates. Government A, Editor, Canberra.

\section{Appendix}

All costings are in US Dollars (Australian Dollars in parentheses).

Average annual cost of program from 2009-2012 = \$716,939 $(\$ 769,000)$.

Site 1 (St George Hospital) average annual cost 2007-2012 = \$414,874 $(\$ 445,000)$.

Site 2 (The Sutherland Hospital) average annual cost 2009-2012 = \$302,065 $(\$ 324,000)$.

Wage of 1 full time equivalent (FTE) nursing staff and physiotherapist: \$57,803 - 72,719 (\$62,000 - \$78,000) per annum.

Number of staff:

-Nurse Unit Manager, 1.0 FTE

-Clinical Nurse Specialist (one full time, three part time), 2.76 FTE

-Registered Nurse (two part time), 0.92 FTE

-Physiotherapist (one full time, two part time), 1.71 FTE

-Administration officer (one full time), 1.0 FTE

-Total: 7.39 full time equivalents (FTE)

Motor vehicle costs per annum: \$12,586 $(\$ 13,500)$ per annum

Consumables (IV cannulas, antibiotics, INR strips, syringes, Micropore tape, cotton balls etc): \$2499 (\$2,680) per annum. 


\section{Submit or recommend next manuscript to SCIRP and we will provide best service for you:}

Accepting pre-submission inquiries through Email, Facebook, LinkedIn, Twitter, etc.

A wide selection of journals (inclusive of 9 subjects, more than 200 journals)

Providing 24-hour high-quality service

User-friendly online submission system

Fair and swift peer-review system

Efficient typesetting and proofreading procedure

Display of the result of downloads and visits, as well as the number of cited articles

Maximum dissemination of your research work

Submit your manuscript at: http://papersubmission.scirp.org/ 